\title{
A Hedging Strategy for New Zealand's Exporters in Transaction Exposure to Currency Risk
}

\author{
Kam Fong Chan \\ University of Queensland, Australia \\ Christopher Gan \\ Lincoln University, New Zealand \\ Patricia A. McGraw \\ Lincoln University, New Zealand
}

\begin{abstract}
A survey on derivative usage and financial risk management in New Zealand shows that the currency forward is the most frequently used derivatives in hedging transaction exposure. This paper examines whether forwards performs better than over-the-counter option for a New Zealand exporter in hedging NZD/USD transaction exposure. This research adopts Hsin, Kuo and Lee's (1994) model of hedging effectiveness which maximizes the exporter's expected negative exponential utility function to compare and evaluate the ex-ante hedging effectiveness of both forwards and options synthetic forwards. The results show that prior to the 1997 A sian Crisis, forwards are marginally more effective than options synthetic forwards for an ordinary risk-averse exporter to hedge against her/his 1, 3, 6 and 12-month transaction exposures. However, during and after the 1997 Asian Crisis, options synthetic forwards are more effective than forwards for hedging exposures of 1,3 and 6 months. The results are robust to the exporter's degree of absolute risk aversion (JEL G1, G11).
\end{abstract}

Keywords: forwards, hedging effectiveness, optimal hedge ratio, options synthetic forwards, utility maximization.

*The authors are grateful to Professor Phil Gray (from Queensland University Business School, Australia) helpful suggestions and computation advice. All errors remain ours alone.

(Multinational Finance Journal, 2003, vol. 7, no. $1 \& 2$, pp. 25-54)

CMultinational Finance Society, a nonprofit corporation. All rights reserved.

DOI: $10.17578 / 7-1 / 2-2$ 


\section{Introduction}

New Zealand's transition from fixed to floating exchange rates since March 1984 has exposed virtually all New Zealand exporters to transaction exposure to volatile currency risk. To hedge against currency risk, the exporters can use different types of currency derivatives, with the notable ones being the forwards, futures, swaps and options. In a recent survey on derivatives usage and financial risk management by both listed and non-listed New Zealand firms, Prevost, Rose and Miller (2000) report that over $70 \%$ of 104 respondents who hedged used forwards to minimize their foreign currency risk exposures. Over-the-counter (OTC) options are the next most preferred currency derivatives with nearly $40 \%$ of the respondents indicating their usage. Comparable findings are also drawn by a previous New Zealand survey conducted by Berkman, Bradbury and Magan (1997). Prevost, Rose and Miller (2000) further reveal transaction exposure as the most relevant exposure in New Zealand. Further segmentation of transaction exposure hedging into different types of derivatives indicates that forwards are used most prevalently in New Zealand (approximately 40\% used), followed by OTC options (25\%). Thus, forwards and OTC options are the first and second derivative instruments most preferred by New Zealand non-financial firms to hedge against currency risk, with transaction exposure as their main objectives. It remains to be seen if currency forwards are more effective than OTC options in hedging transaction exposure.

This paper examines whether currency forwards or OTC options provides New Zealand exporters with the optimum hedging effectiveness to hedge NZD/USD transaction exposure. This research adopts Hsin, Kuo and Lee's (1994) model of hedging effectiveness $\left(H E_{H K L}\right)$, which is based on the theory of expected utility maximization and considers both the risk-returns dimension and the exporters' risk preferences in hedging. This allows discretionary hedging and avoids most of the problems incurred when using the traditional methods, which depend on the Sharpe index and variance minimization theory. ${ }^{1}$

There have been relatively few studies to compare the hedging effectiveness between currency forwards and OTC options. Most previous works compare the hedging effectiveness of currency futures and exchange-traded options (see Chang and Shanker [1986]; Hsin, Kuo

1. See discussion in section II. 
and Lee [1994] and DeMaskey [1995]). Since OTC options and forwards are frequently used in New Zealand compared to exchangetraded contracts, this research evaluates the hedging effectiveness of the aforementioned derivatives. Besides, Lien (1997) and Kwok (1987) note that although most previous researches compare the hedging effectiveness of currency futures and options, the same conclusions (that currency futures will outperform currency options in terms of hedging effectiveness) are expected to carry over to the case between currency forwards and options. As discussed above, it remains to be seen if New Zealand non-listed companies prefer to use forwards to OTC options due to the former superior hedging effectiveness.

The remainder of the paper is organized as follows. Section II reviews previous work on currency hedging effectiveness. Section III describes the data and methodology. Section IV discusses the theoretical models by which the hedge ratio and hedging effectiveness could be scrutinized. Section V discusses the findings of the research and section VI concludes the research.

\section{Previous Literature on Hedging Effectiveness}

Previous works on hedging effectiveness is based on the traditional or naïve strategy, which assumes the exporter to be extremely risk averse and wants to completely eliminate all her currency risk exposures. She typically takes a derivative position equal in magnitude but of opposite sign to her position in the cash market. Hence, the optimal hedge ratio $\left(b_{\text {naive }}^{*}\right)$ is $1: 1$. Working $(1953 \mathrm{a}, 1962)$ reformulates the hedging theory by portraying the exporter as a risk taker who behaves like a part-time speculator and focuses on profit maximization. Accordingly, the exporter adopts a selective (discretionary) hedging strategy by putting on a hedge in anticipation of a favourable relative price change in the spot and derivative prices. The hedging effectiveness depends on the inequalities between the movements of the spot and derivative prices and on reasonable expectation of such inequalities (Working, [1953b]). This hedging effectiveness measure is later redefined by Junkus and Lee (1985) as an increase in gross profit over the traditional hedge.

Johnson (1960), Stein (1961) and Ederington (1979) synthesize both naïve and Working's theories to view hedging as an extension of Markowitz's portfolio theory. By applying the variance-minimization (V-M) approach, the exporter's (hedger's) objective is to minimize the 
variance of the expected return on a hedged portfolio, which includes both spot and hedge instrument holdings. Accordingly, the measure of hedging effectiveness $\left(H E_{V M}\right)$ is defined as the percentage reduction in the portfolio variance from maintaining a hedged rather than an unhedged position. DeMaskey (1995) uses this concept to compare the hedging effectiveness of currency futures and exchange traded options for covered (certain) and uncovered (anticipatory) currency positions for the Pound (GBP), Deutsche Mark (DEM), Yen (JPY), Swiss Franc (CHF) and Canadian dollar (CAD). The author finds currency futures to be more effective than options synthetic futures for the covered positions. For the uncovered position, the author uses Witt, Schroeder and Hayenga's (1987) modified V-M model to show options as the preferred hedging instrument. In all cases, the optimal hedge ratios of $b_{V M}^{*}$ are less than one. Chang and Shanker (1986) also find similar conclusions.

The V-M approach is criticized for ignoring the expected return dimension. Howard and D'Antonio (1984) reformulate the measure of hedging effectiveness by incorporating both risk and return components. Their $H E_{H D}$ is defined as the ratio of the Sharpe Ratio's differential return of the hedged portfolio (comprising the optimal proportions of derivative and spot cash market) to the Sharpe Ratio's differential return of the unhedged spot portfolio. Hsin, Kuo and Lee (1994) argue that the Sharpe Ratio is a proper effectiveness measure only when the excess return of both hedged and unhedged spot portfolio are positive. Further, the second order condition can be violated either when the excess returns of the unhedged spot portfolio and risk-free rate are positive or when both are negative. As a result, the hedging effectiveness models based on the Sharpe ratio (see Howard and D'Antonio [1984, 1987]; Chang and Shanker $[1986,1987])$ are considered weak. In addition, weakly risk averse exporters will adopt hedge ratios and consequently hedging decisions that differ from those chosen by strongly risk averse exporters (Stein [1961]). This notion has been overlooked in HowardD'Antonio and Chang-Shanker's models.

An alternative measure of hedging effectiveness is based on the theory of expected utility maximization (U-M). The objective is for the exporter to choose $X_{S}$ and $X_{D}$ units of spot cash and derivatives, respectively, to maximize her expected utility function that is completely ordered by her portfolio's mean and variance. The exporter is assumed to be willing to pay an amount equal to the difference between the increased expected cash revenue and increase in risk 
weighted by her degree of absolute risk aversion (ARA), a term popularized by Pratt (1964). Hence, discretionary hedges are allowed according to the exporter's risk aversion behaviour. According to Anderson and Danthine (1980, 1981), the optimal cash and futures positions in the portfolio are generally determined simultaneously and the optimal hedge can be viewed as the sum of a risk minimizing position and a speculative position. Hammer (1988) notes that Pratt's ARA, which is the risk premium per unit of variance, is a more acceptable measure of risk aversion than Howard and D'Antonio's (1984) Sharpe Ratio model, which is the risk premium per unit of standard deviation. Furthermore, the ARA might be a reasonable surrogate for portfolio positions desired by different investors having different utility functions, as evidenced in Kallberg and Ziemba's (1983) study.

Hsin, Kuo and Lee (1994) employ the utility maximization approach to compare the hedging effectiveness of foreign currency futures and exchange-traded options. The hedging effectiveness $\left(H E_{H K L}\right)$ is defined as the difference of the certainty equivalent return between the hedged and unhedged spot position. Hsin, Kuo and Lee (1994) postulate that Gjerde's (1987) hedging effectiveness model, $H E_{G 2}$, breaks down when the expected return of the initial expected spot position, $E\left(R_{S}\right)$, is negative. Under this condition, a hedged position that supposedly yield higher utility will turn out to have a lower $H E_{G 2}$, leading to an ambiguous conclusion. However, the $H E_{H K L}$ is robust to the sign of $E\left(R_{S}\right)$ and thus corrects the inconsistency of $H E_{G 2}$. The $H E_{H K L}$ also overcomes the aforementioned drawbacks found in those measures that are based on the Sharpe ratio. In addition, the optimal hedge ratio, $b_{H K L}^{*}$, does not contain the expected return of spot foreign currency parameter, hence mitigating any necessity to forecast the direction of the spot price change as in Howard and D'Antonio's (1984), Gjerde's (1987) and Hammer's (1988) models.

Hsin, Kuo and Lee (1994) examine the effectiveness measure of futures, option synthetic futures as well as options using delta and delta + gamma hedging on the GBP, DEM, JPY and CHF. Two strategies are employed to determine the daily hedge ratios: one is the daily rebalancing method and the other is the buy-and-hold strategy. The authors results show that for the daily rebalancing method, all the hedges with currency futures yield positive $H E_{H K L}$ 's. In contrast, the hedges with option synthetic futures consistently produce lower or even negative $H E_{H K L}$ 's for some of the longer hedges, indicating ineffective 
hedging. A similar conclusion is reached when the buy-and-hold strategy is employed, prompting Hsin, Kuo and Lee (1994) to suggest that the buy-and-hold strategy is a better hedging strategy if transaction costs are considered. The inferiority of currency options continues with delta and delta + gamma hedges. However, these hedges are less effective with the buy-and-hold strategy. The overall results seem to be robust to the degree of risk aversion.

\section{Data Methodology}

This research focuses on comparing the hedging effectiveness of currency forwards and OTC options in hedging NZD/USD transaction exposures. The data consist of average bid-ask spot prices provided by DataStream for the period of July 1, 1985 to June 30, 2000. ${ }^{2}$ This research employs the modified Black-Scholes model to simulate 1-, 3-, 6-and 12-month OTC European options. Such simulations represent the best estimate for the price of the currency options in the OTC market had they been traded freely., ${ }^{3,5}$ Construction of the options synthetic

2. These whole sample periods are for the estimations of (1) the volatility term in the currency option model, (2) the optimal hedge period and (3) the $H E_{H K L}$.

3. The modified Black-Scholes model for European currency options refers to either the model of Biger and Hull (1983) or the model of Garman and Kohlhagen (1983). In these models, the spot exchange rate replaces the stock price in the standard Black-Scholes model and the foreign interest rate enter as an additional variable.

4. The OTC options for the NZD/USD are not observable in the New Zealand secondary market. Grabbe (1983) notes that the OTC currency options market is often invisible as financial institutions are reluctant to widely publish any data regarding their activities. This is confirmed when six New Zealand banks that offer the currency options price-making facilities responded negatively to inquiries concerning the data about their OTC currency options. In addition, the New Zealand foreign exchange market is thinly traded. For these reasons the data on OTC currency options is simulated.

5. Shastri and Tandon (1986) use the modified Black-Scholes model to test the efficiency of the market for foreign currency options. Evidence from ex-ante tests suggest that the foreign currency market of their settings is efficient during the period investigated. Sarwar and Krehbiel (2000) examine the out-of-sample performance of the stochastic volatility and modified Black-Scholes models in valuing European currency call options written on the GBP. Results from mean error, absolute error and root mean square error suggest that both models yield virtually identical values for at-the-money options. Heston (1993) also notes that for at-the-money options, the modified Black-Scholes and stochastic volatility model produce 
forwards follows after the derivation of the options prices. The options synthetic forwards are used instead of the options prices for two reasons: (1) it allows explicit comparisons between options and forwards, and (2) one can examine if options can cause redundancy to the forwards market. ${ }^{6}$ This research includes the forward rates data of 1, 3, 6 and 12-month for the period of July 1, 1990 to June 30, 2000. ${ }^{7}$ The forward prices are the bid prices as the exporter is assumed to be shorting his/her transaction exposure to foreign currency receipts. Once all the data are available, the $b_{H K L}^{*}$ 's can be immediately calculated for both derivatives using some ex-post sample data. These estimated $b_{H K L}^{*}$ 's are finally applied to ex-ante sample data to calculate the $H E_{H K L}$ 's which in turn allows for comparing the hedging effectiveness of derivatives.

This research builds on several assumptions. First, since the exporter is exposed to transaction exposure, she is assumed to receive a certain amount of foreign currency $\left(X_{S}\right)$ in 1, 3, 6 or 12-month's time with no default (credit) risk. Second, the exporter is assumed to adopt a sell-andhold strategy (i.e., the exporter enters into a derivative contract and holds it until the end of the hedging period before selling the foreign currency). Third, most OTC options are European as its nature (i.e., it can only be exercised at the expiration of the options) provide less risk for the financial institutions who are usually the sellers of the derivatives (Daigler [1994]). Accordingly, this research only considers European OTC currency options. Fourth, this research only simulates at-the-money options due to its popularity among the traders. ${ }^{8}$

identical option prices. Sarwar and Krehbiel (2000) further note that the out-of-sample pricing performance of the modified Black-Scholes model is either similar or better than that of the stochastic volatility model when they are compared with the three aforementioned statistical loss functions and regression tests of the degree of association between the actual prices and the model-based prices. Based on these empirical results and coupled with its nature which is less computational extensive compared to other models, we decide to use the modified Black-Scholes model in our simulation to represent the actual at-the-money European NZD/USD options prices.

6. Cox and Rubenstein (1985) and Chang and Shanker (1986) demonstrate that selling currency forwards can be duplicated synthetically by combining put and call options with either borrowing or lending an ap propriate amount. A currency option synthetic forward may effectively replace a forward contract in hedging transaction exposure to currency risk if the hedging effectiveness of the former is higher than that of the latter. Otherwise, each tool can serve a specialized market niche.

7. These sample periods are only for the estimation of (1) the optimal hedge period and (2) the $H E_{H K L}$.

8. Das (1997) notes that traders typically trade in short-dated at-the-money options to 


\section{Theoretical Models}

As discussed in section III, this research employs the modified BlackScholes model to simulate the European OTC option prices. Its closed form solution is defined as:

$$
c_{e}=S e^{-r f T} N\left(d_{1}\right)-K e^{-r f T} N\left(D_{2}\right),
$$

where $N(d)=$ standard normal distribution,

$$
\begin{gathered}
d_{1}=\left[\ln \left(S_{t} / K\right)+\left(r f-r f^{*}+h_{t}^{2} / 2\right)\right] / h_{r} \sqrt{T}, \\
d_{2}=d_{1}-h_{2} \sqrt{T}
\end{gathered}
$$

and

$r f=$ domestic risk-free interest rate

$r f^{*}=$ foreign risk-free interest rate

$T=$ time to maturity

$h_{\mathrm{t}}=$ foreign currency volatility

$S_{t}=$ spot exchange rate of NZD/USD

$K=$ exercise price

$e=$ exponential term

All the terms in the above equations are observable except for the volatility term of $h_{t}$. This research employs Bollerslev's (1986) GARCH $(1,1)$ model to estimate the $h_{t}$ and then plugs it into the modified BlackScholes model. This ad-hoc technique is consistent with many realworld practitioners who often substitute the variance input in the BlackScholes formula with the expected variance from the GARCH model (Engle, Kane and Noh [1994]). ${ }^{9}$ In addition, West, Edison and Cho

manage and rebalance their Greeks.

9. Heston (1993) and Duan (1995) provide alternative stochastic volatility models to price currency options. However, as noted in footnote 5 , stochastic volatility options pricing models do not yield substantial improvement over the modified Black-Scholes model for atthe-money European options. As such, this research uses the modified Black-Scholes options pricing model with its volatility term is estimated using the $\operatorname{GARCH}(1,1)$. The test based on option prices which is simulated using Heston's (1993) and Duan's (1995) models is left for future research. 
(1993), Engle, Hong, Kane and Noh (1993) as well as Engle, Kane and Noh (1993a; b) use some utility-based and profit-based measurements to suggest that the GARCH-type forecasts tend to be superior than other volatility models in estimating the conditional variance. The mean equation is defined as follows:

$$
R_{t}=\theta+\epsilon_{t}
$$

where $R_{t}=$ returns (in logarithm form) of hedged/unhedged (spot) portfolio, $\epsilon_{t}$ is assumed to follow a normal distribution of $\left(0, h_{t}^{2}\right)$ and conditional variance equations for the $\operatorname{GARCH}(1,1)$ model is defined as:

$$
h_{t}^{2}=\alpha+\alpha \varepsilon_{t-1}^{2}+\beta h_{t-1}^{2}
$$

The daily forecast of $h_{t}$ is used as an estimate for the volatility term in the modified Black-Scholes model for forecast horizons of 1,3, 6 and 12 -month period. The estimation of the $h_{t}^{2}$ is based on the past 4 years daily data (i.e. 1,044 observations). ${ }^{10}$ Since it would be more realistic to assume the exporter uses more recent information to calculate the $h_{t}^{2}$, the moving-window procedure is adopted. It begins by estimating the $h_{t}^{2}$ using the first 1044 observations. This estimate is then used to forecast the future $h_{t}^{2}$ of the 1, 3,6 and 2-month options prices. As the volatility term of the options model needs to be in annual terms, the $h_{t}$ will be annualized by multiplying it by the square root of 260 , which is the average number of non-weekend days in one year. ${ }^{11}$ After this first

10. Figlewski (1999) observes that the in-sample data used for volatility forecasting should be at least 4 times longer than the forecast horizon. As the longest forecast horizon in this research is 1 year, the use of 4 years of in-sample estimation data should satisfy Figlewski's (1999) criteria. Moreover, DataStream only started reporting the NZD/USD spot prices from January 1985 onwards as the NZD/USD was only floated from March 1984.

11. Diebold, Hickman, Inoue and Schuermann (1997) note that the common practice of converting 1-day volatility estimates to $h$-day estimates by scaling by the square root of $h$ is inappropriate and produces overestimates of the variability of long-horizon volatility. They suggest that if $h$-day volatilities are of interest, it makes sense to use an $h$-day model. If we were to follow Diebold et al's (1997) suggestion, we would have insufficient in-sample period to estimate even the GARCH $(1,1)$ volatility of the shortest forecast horizon of 1month since the NZD/USD spot data is only made available from January 1985 . Moreover, Diebold et al (1997) conclude that the scaling procedure is appropriate under certain conditions and even if these conditions are violated, the scaling procedure produces results that are on average correct. Furthermore, the scaling process is consistent with what the realworld practitioners and academic theorists would usually do. As such, this research continues 
estimation, the $h_{t}^{2}$ is re-estimated by subtracting the first observation and adding the next observation. In other words, the $2^{\text {nd }}$ to $1045^{\text {th }}$ observations are employed, thus keeping the window size of 1044 observations constant. This procedure is carried out for all subsequent periods. Using all these annualized $h_{t}^{2}$, s, coupled with other observable parameters of the risk-free interest rates and spot currency, equation 1 is utilized to simulate the daily option prices.

The put option equation is then immediately derived using the putcall-parity defined as follows:

$$
p_{e}=K e^{-r t} N\left(-d_{2}\right)-S_{t} e^{-\gamma f^{t} t} N\left(-d_{1}\right),
$$

The construction of options synthetic forwards follows once the European call and put prices are simulated. A short position in the forward markets can be duplicated by a short position in a call, a long position in a put and by either borrowing or lending $\left(F_{(t, t+1)}-K\right) /(1+$ $r f)^{\mathrm{T}}$. If $K>F_{(t, t+1)}$, then $\left(F_{(t, t+1)}-K\right) /(1+r f)^{T}$ is borrowed. If $K<$ $F_{(t, t+1)}$, then $\left(F_{(t, t+1)}-K\right) /(1+r f)^{T}$ is lent.

Having obtained both forwards and options synthetic forwards data, the next step is to derive the $b_{H K L}^{*}$. As with Hsin, Kuo and Lee (1994), this research adopts Pratt's (1964) constant ARA. Pratt (1964) envisions the expected utility function as continuous and in negative exponential form. A negative exponential utility function is justified based on its intuitive appeal. The exporter is assumed to behave rationally by preferring more return to less (positive marginal utility) and her marginal utility decreases as she has more and more returns. The expected utility form is expressed as follows:

$$
U(R)=-e^{-c R},
$$

where $c=$ constant.

The $\operatorname{ARA}(\Theta)$ is interpreted as a function of $-U(R) / U(R)$. Accordingly, the $\Theta$ is equal to the constant $c$. Pratt (1964:127) notes that the sign of $U(R)$ is vital. A negative (positive) sign for all $(R)$ implies strict concavity (convexity) and hence unwillingness (willingness) to accept any actuarially neutral risk with any assets. Since $U(R)$ has a negative sign, the exporter's expected utility function is strictly concave

to use the scaling procedure in the simulation process. 
(implying risk-averse behaviour) and all portfolios can be ordered in terms of their means and variance of returns. This results in a monotone increasing function of the expected utility of $V[E(R), \delta, \Theta]$, with the usual normality assumption being imposed. Mathematically, the utility function is

$$
\begin{gathered}
V\left[E\left(R_{H}\right), \delta_{H}, \Theta\right]=E\left(R_{H}\right)-1 / 2 \delta_{H}^{2} \Theta, \\
V\left[E\left(R_{S}\right), \delta_{S}, \Theta\right]=E\left(R_{S}\right)-1 / 2 \delta_{S}^{2} \Theta
\end{gathered}
$$

where

$$
\begin{gathered}
E\left(R_{H}\right)=\frac{X_{S} S_{T} E\left(R_{S}\right)+X_{F} F_{(t, t+1)} E\left(R_{F}\right)}{X_{S S_{t}}}, \\
\delta_{H}^{2}=\frac{X_{S}^{2} S_{t}^{2} \delta_{S}^{2}+X_{F}^{2} F_{(t, t+1)}^{2} \delta_{F}^{2}+2 X_{s} X_{F} S_{t} F_{(t, t+1)} \delta_{s} \delta_{F} \rho}{X_{S}^{2} S_{t}^{2}},
\end{gathered}
$$

and the subscript $H$ denotes the hedged portfolio, $S$ is the spot cash (unhedged) position, and:

$F_{(t t+1)}=1,3,6$ or 12-month forward (option synthetic forward) price initiated at time $t$.

$R_{S} \quad=\operatorname{Ln}\left(S_{t+1} / S_{t}\right)$ (percent).

$R_{F} \quad=\operatorname{Ln}\left(F_{(t, t+1)} / F_{(t-1, t)}\right)$ (percent).

$\delta_{S}, \delta_{F}=$ standard deviation of the returns (percent) for the spot and derivatives, respectively

$\rho=$ correlation between the returns (percent) of the spot and derivatives.

The optimal hedging is achieved by deriving the first order condition (FOC) for $V\left[E\left(R_{H}\right), \delta_{H}, \Theta\right]$ with respect to $X_{F}$ and solving for the $b_{H K L}^{*}$, where $X_{F}=X_{S}\left(b_{H K L}^{*}\right)$.

$$
b_{H X I}^{*}=\left[\frac{S_{t}}{F_{(t+1)}}\right]\left[\frac{E\left(R_{F}\right)}{\Theta \delta_{F}^{2}}-\rho\left(\delta_{S} / \delta_{F}\right)\right] .
$$

A $b_{H K L}^{*}$ within the range of 0 to 1 indicates that the exporter should 
hedge less than the full amount of transaction exposure she is facing, whilst a $b_{H K L}^{*}>1$ signifies that she should hedge more than her full transaction exposure. The second order condition (SOC) for the optimal hedging decision is:

$$
-\theta\left\{F_{(t++1)}^{2} \delta_{F}^{2}\right\} /\left(X_{S}^{2} S_{t}^{2}\right\}<0
$$

The SOC for $V\left[E\left(R_{H}\right), \delta_{H}, \Theta\right]$ is achieved so long as the constant $\Theta$ is a positive value, which is the case for any risk-averse exporter. This implicitly verifies the validity behind the assumption regarding the exporter's utility function, which is assumed to be in negative exponential form, and therefore producing a constant positive ARA = $c$. The inclusion of ARA in the $b_{H K L}^{*}$ suggests that the optimal hedging decision is specific to the exporter. For an extremely risk-averse exporter with a $\Theta$ approaching infinity, equation 12 is then reduced to $\left.-\left\{S_{T} / F_{(t, t+1)}\right\}\left\{\delta_{S F} / \delta_{F}^{2}\right)\right\}$. This $b *$ is similar to the $b_{V M}^{*}$, hence demonstrating the flexibility of Hsin, Kuo and Lee (1994) non-nested model to extend to the variance-minimization approach. Consistent with Hsin, Kuo and Lee (1994), we use $\Theta=2.0$ for the optimal hedge ratios for currency forwards and options synthetic forwards, with $\Theta=0.5$ and $\Theta=6.0$ employed as robustness tests for least and highly risk-averse exporters respectively. In addition, $X_{S}$ is assumed to equal to unity as this research is concerned with transaction (contractual) exposure to foreign currency risk.

In order to maximize their mean-variance dependent utilities, the exporters are assumed to make their optimal hedging decision by using $b_{H K L}^{*}$ for currency forward and options synthetic forwards. This $b_{H K L}^{*}$ is then applied to the ex-ante sample data to assess the hedging strategy by using the hedging effectiveness measure of $H E_{H K L}$. $H E_{H K L}$ is defined as the excess of the maximized mean-variance dependent expected utilities of the hedged portfolio (that contains a proportion of both currency derivatives and spot cash) to the mean-variance dependent expected utilities when the portfolio is unhedged (that contains only the spot cash position). Formally, it is defined as:

$$
\begin{gathered}
H E_{Z X I}=V\left[E\left(R_{H}\right), \delta_{H}, \Theta\right]-V\left[E\left(R_{S}\right), \delta_{S}, \Theta\right] \\
=\left[E\left(R_{H}\right)-1 / 2 \delta_{H}^{2} \Theta\right]-V\left[E\left(R_{s}\right)-1 / 2 \delta_{S}^{2} \Theta\right] .
\end{gathered}
$$


A positive value of $H E_{H K L}$ means the hedging strategy is effective, a zero value of $H E_{H K L}$ means indifference between the hedged and unhedged position, and a negative measure of $H E_{H K L}$ indicates an ineffective hedging strategy. Finally, the $H E_{H K L}$ for currency forwards is compared to that of options synthetic forwards to examine if the former provides superior hedging effectiveness than the latter.

The calculation of $b_{H K L}^{*}$ requires the current prices of the spot and forwards (options synthetic forwards) and the estimates for $E\left(R_{F}\right), \delta_{S}$, $\delta_{F}$ and $\rho$. Meanwhile, the $H E_{H K L}$ requires all the parameters as in the $b_{H K L}^{*}$ plus the estimates for the $E\left(R_{S}\right)$. In order to provide the estimations for these models, this research adopts the ex-ante approach as proposed by De Jong, De Roon and Veld (1997) and Hsin Kuo and Lee (1994). It entails the assessment of the optimal hedge ratio using the in-sample (estimation) data, which is then assessed with the hedging effectiveness measure using the out-of-sample (hedge) data. Assuming the daily returns on the spot and forwards (options synthetic forwards) are independently and identically distributed over time, the in-sample estimates for the $E\left(R_{F}\right), \delta_{S}, \delta_{F}$ and $\rho$ of the $b_{H K L}^{*}$ are calculated from the prices over the $d$ non-weekend days preceding the hedging day for each time a hedge is placed. We choose the $d$ to equal to 4 years of in-sample data (which consists of 1044 observations). This research also adopts the moving-window approach to calculate the daily $b_{H K L}^{*}$, and $H E_{H K L}$. This moving-window procedure is appealing as it allows the exporter to use up-to-date current information to estimate the hedge ratios. In order to mitigate any concern that this research might be drawing its implication based on a one-off incident, the daily $b_{H K L}^{*}$ and $H E_{H K L}$ are averaged annually at the year end of each July, starting from July 1994. As such, the optimal hedge ratio and hedging effectiveness can be assessed annually for 3 years prior to and after the Asian Crisis, which occurred at July 2, 1997.

\section{Empirical Results}

Table 1 and figure 1a tabulates the descriptive statistics and time-series movements for the NZD/USD over the periods of $1 / 7 / 1985$ to $30 / 6 / 2000$. For the whole sample period of $1 / 7 / 1985$ to $30 / 6 / 2000$, the mean of the spot rate is 1.72 and the average of its daily log price changes is positive at $8.5 \times 10^{-6}$. This suggests that the NZD/USD generally appreciates over the whole sample period. In the pre-Asian 
Multinational Finance Journal

PLACE TABLE 1 HERE 


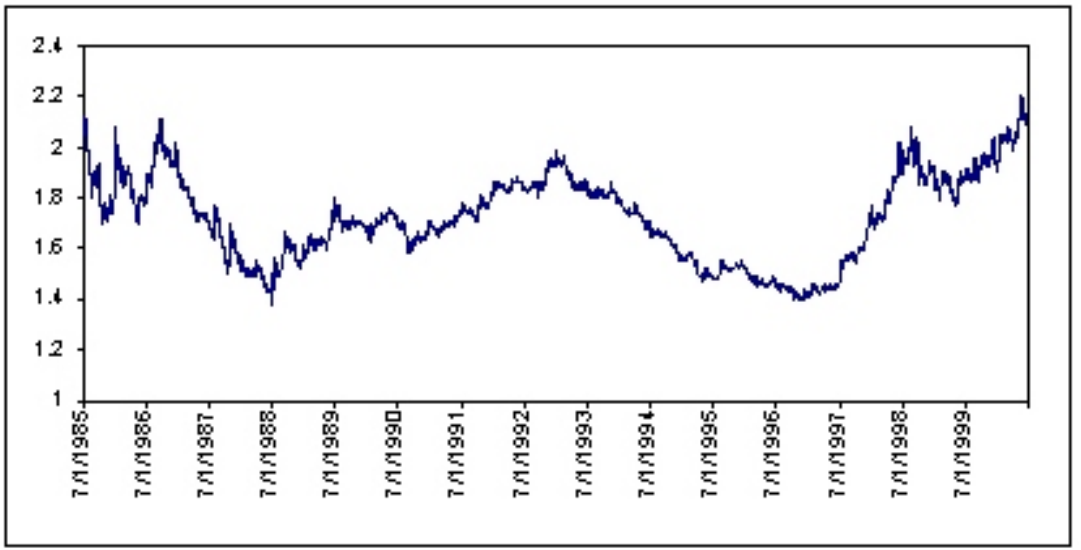

FIGURE 1a.-NZD/USD spot rate for the sample period 1.7.1985 to 30.6.2000.

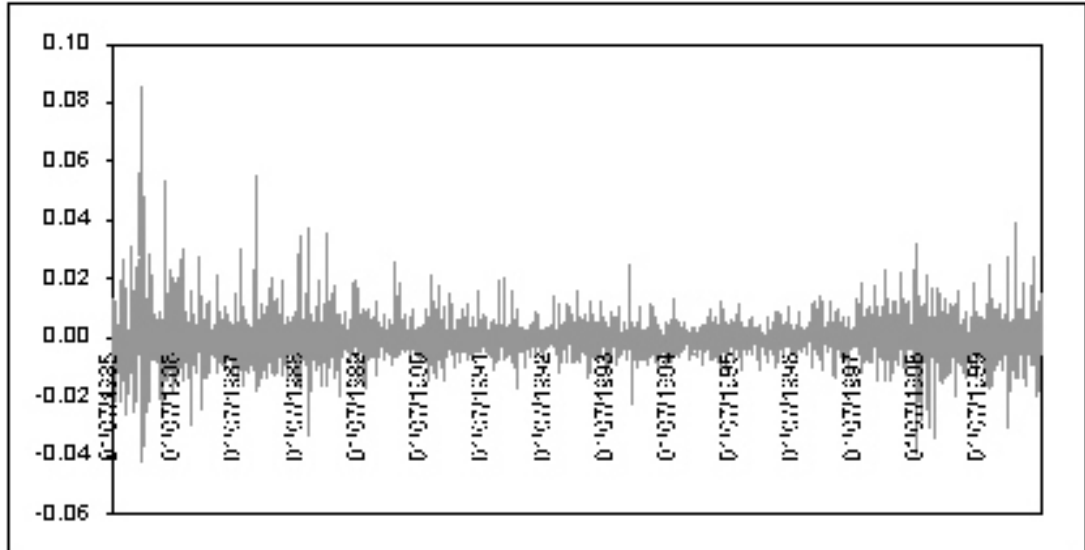

FIGURE 1b.- The returns (in natural logarithm) of NZD/USD spot rate for the sample period 1.7.1985 to 30.6.2000.

Crisis period (1.7.1994 to 1.7.1997), the average daily log price changes are negative at $-1.7 \times 10^{-4}$, whilst in the post-Asian Crisis period (2.7.1997 to 30.6.2000), the average daily log price changes are positive at $4.7 \times 10^{-4}$. In other words, the NZD/USD depreciates during the preAsian Crisis but appreciates during the post-Asian Crisis. The daily log price changes also tend to produce slight skewness but massive excess kurtosis for all the whole sample and sub-sample periods considered. Such heavy tailed behaviour confirms previous studies on exchange 
rates (see Boothe and Glassman [1987] and Hsieh [1988, 1989]). Accordingly, the Jacque-Bera's (1987) test rejects the null hypothesis of normality for all cases. In figure $1 b$, the daily log price changes clearly exhibit significant volatility clustering (i.e., ARCH effects). This is confirmed through the formal statistical analysis of Engle's (1982) Lagrange Multiplier (LM) procedure. Consistent with Hsieh (1989) and Bailie and Bollerslev (1989) who find strong ARCH effects in the daily foreign exchange rate, this research also observe that the null hypothesis of no ARCH (1) effect is consistently rejected at all times. ${ }^{12}$

The "stylized facts" for the empirical distribution of the NZD/USD exchange rates can be summarized as follows: it is neither normally nor log-normally distributed. In addition, the volatility term $h_{t}$ is timevarying, which can be explained by the GARCH $(1,1)$ model (Baillie and Bollerslev [1989] and Hsieh [1989]). With this evidence, the conditional mean and variance in equations 4 and 5 are estimated to construct the OTC European options prices and subsequently the options synthetic forwards.

Table 2 tabulates the results of the $b_{H K L}^{*}$ obtained from equation 12 and when the $\Theta$ is set at 2 to represent an ordinary risk-averse exporter. The time-series of the $b_{H K L}^{*}$ are also shown in figure 2. Both table 2 and figure 2 demonstrate that the $b_{H K L}^{*}$ rarely equal to unity. ${ }^{13}$ This supports the results found in Markowitz's hedging theory (Ederington [1979] Naidu and Shin, [1981]), but casts further doubts on the naïve hedging strategy which maintains the optimal hedge ratio is $1: 1$. The hypothesis of Eaker, Fabozzi and Grant (1996) and Ware and Winter (1988) that the optimal hedge ratio for currency forwards should equal to unity is also rejected. In fact, the $b_{H K L}^{*}$ 's are less than one for most of the time; meaning the exporter does not need to hedge all of her exposures in order to achieve optimum hedging effectiveness. This is consistent with the findings by Naidu and Shin (1981), Hill and Schneeweis (1982), Hsin Kuo and Lee (1994) as well as DeMaskey (1995). Figure 2 also shows that except for 1-month hedging horizon, the average $b_{H K L}^{*}$ 's of the forwards are generally higher than that of the options synthetic

12. The moving-window results for the ARCH effect are not shown due to space constraint. They are available from the first author upon request.

13. This research tests the null hypothesis that the $b_{H K L}^{*}$ is equal to unity by using Wald test and restricting the mean of the $b_{H K L}^{*}$ to equal to one. Results from $F$-statistics and $C h i$ square statistics show that the null hypothesis is rejected at $5 \%$ level for all the forwards and options synthetic forwards for the whole sample and sub-sample periods. 
Hedging for New Zealand's Exporters

PLACE TABLE 2A HERE 
Multinational Finance Journal

PLACE TABLE 2B HERE 


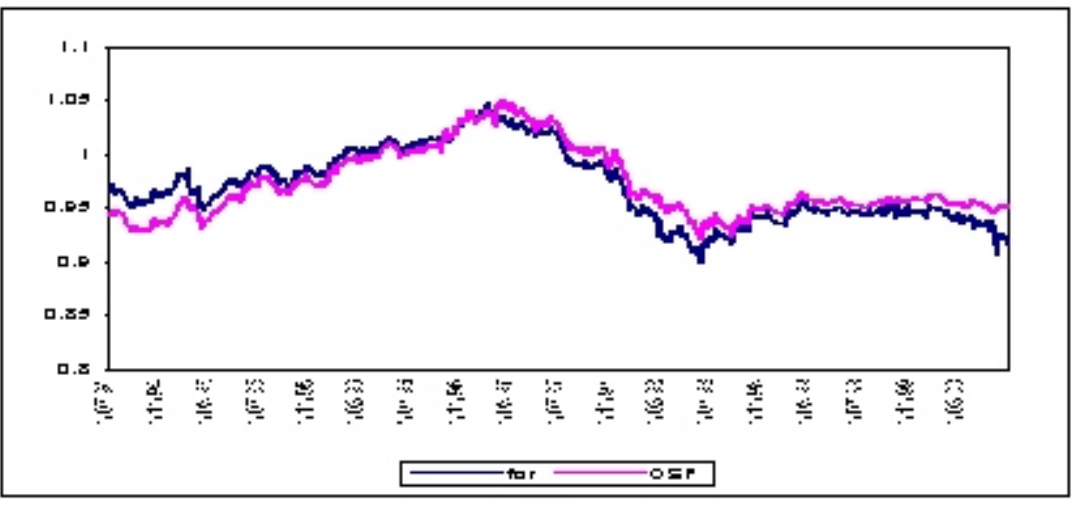

FIGURE $2 \mathrm{a} .-b_{H K L}^{*}$ or forwards and options synthetic forwards for 1month hedging horizon.

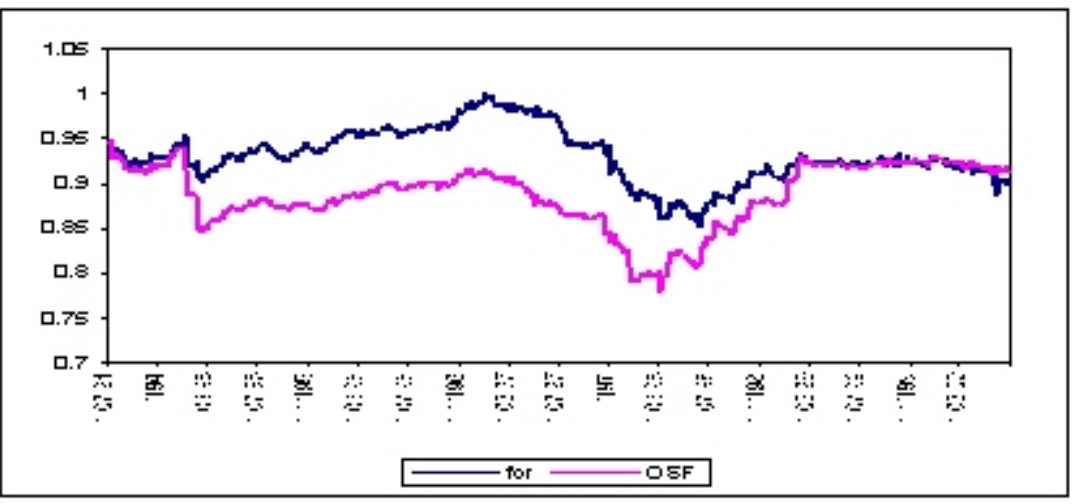

FIGURE $2 \mathrm{~b}-b_{H K L}^{*}$ or forwards and options synthetic forwards for 3month hedging horizon.

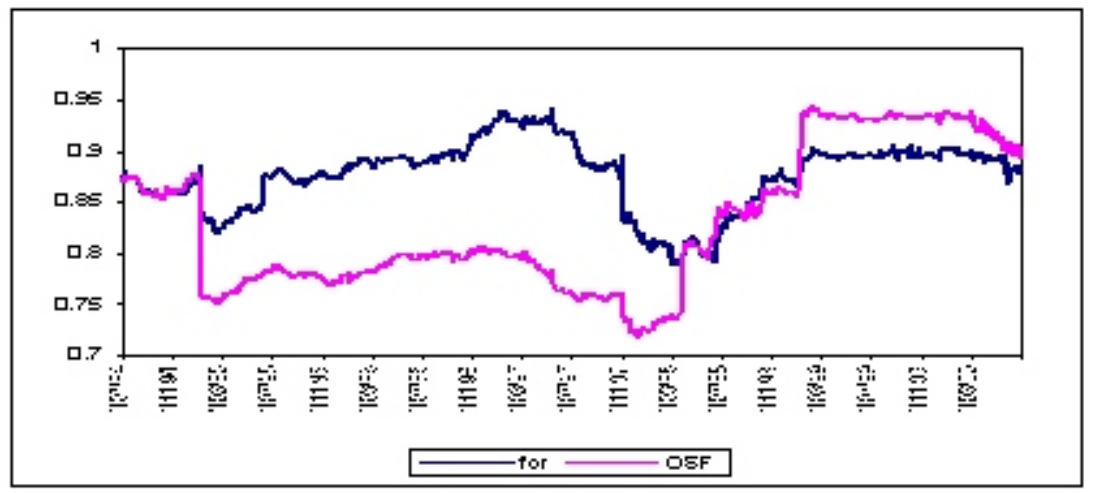

FIGURE $2 c-b_{H K L}^{*}$ or forwards and options synthetic forwards for 6 month hedging horizon. 


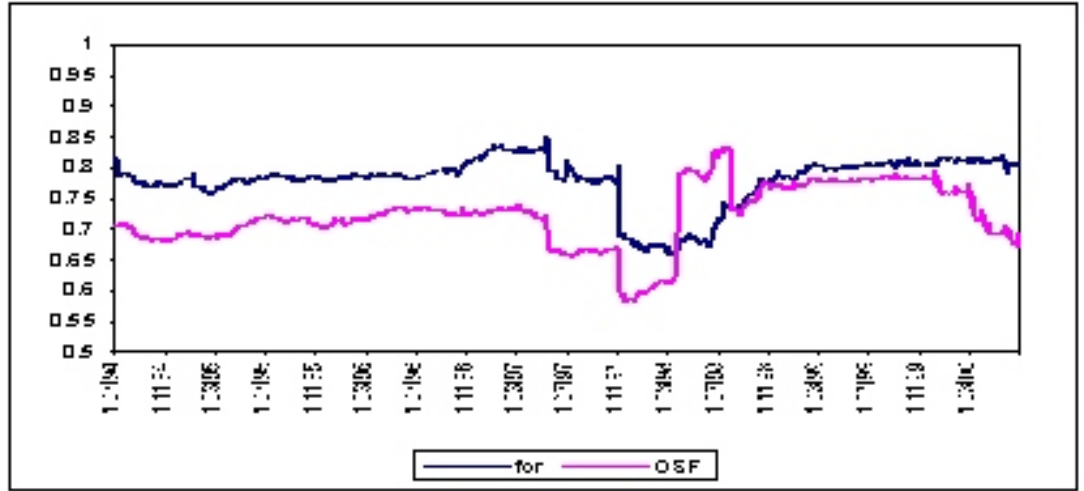

FIGURE $2 \mathrm{~d}-b_{H K L}^{*}$ or forwards and options synthetic forwards for 12month hedging horizon.

forwards. Hence, if the exporter use forwards instead of options, she will need a relatively higher $b_{H K L}^{*}$ 's. The average $b_{H K L}^{*}$ 's of the derivatives seem to decrease with the increases in the hedging horizon periods. For example, for the whole sample period of 1/7/1994 to $30 / 6 / 2000$, the $b_{H K L}^{*}$ is averaged at 0.971 for 1 -month forwards, 0.973 for 1 -month options synthetic forwards, 0.779 for 12 -month forwards and 0.722 for 12 -month options synthetic forwards. Hence, the exporter, on average, may need to hedge $97.1 \%$ and $77.9 \%$ respectively for every 1NZD/USD transaction exposure that she have in 1 month and 12 months time if she use the forwards. In addition, the $b_{H K L}^{*}$ 's tend to decline during the start of the Asian Crisis before it gradually bounces back to its normal value. For example, for the 12-month currency forwards, the $b_{H K L}^{*}$ decreases to as low as 0.658 on $1 / 3 / 1998$, representing a total of $15.53 \%$ decline from its long run mean of 0.779 . This implies that an ordinary risk-averse exporter may not need to hedge as much as she does in normal times in the event of a sudden volatile exchange rate environment such as the 1997 Asian Currency Crisis.

This research also tests the stability of the $b_{H K L}^{*}$ for both the whole sample and sub-sample periods using Philip-Perron's (1988) test. Unlike the standard Augmented Dickey-Fuller's (1979) unit root test, which assumes independence and homogeneity concerning the distribution of the error term, Philip-Perron's test allows the disturbances to be weakly dependent and heterogeneously (including serial correlation) distributed. ${ }^{14}$ Table 2 shows that except for the sub-sample period of

14. The Philip-Perron's test is of $y_{t}=a_{0}^{*}+a_{1}^{*} y_{t-1}+\mu_{t}$ and $y_{t}=a_{0}+a_{1} y_{t-1}+a_{1}(t-T / 2)+\mu_{t}$ 
pre-Asian Crisis for the 1-month options synthetic forwards and 12month forwards, all the $b_{H K L}^{*}$ for the whole sample and sub-sample periods do not reject the null hypothesis of unit root at $5 \%$ level. Hence, the $b_{H K L}^{*}$ is generally unstable, reiterating the importance of an ex-post hedge over an ex-ante hedge.

The measures of hedging effectiveness $\left(H E_{H K L}\right)$ given by (14) are shown in table 2 and figure 3 . All the $H E_{H K L}$ 's are rarely negative, with long-run average is around 0.255 to 0.358 for all the derivatives for the whole sample period. This reiterates that on average, a hedged position is better than an unhedged, spot position by $25.50 \%$ to $35.80 \%$. Table 2 also shows that the $H E_{H K L}$ 's for all the hedging horizons increase substantially during the post Asian Crisis. This comes as no surprise because the exchange rate movements during these periods were very volatile, as demonstrated in figure $1 \mathrm{~b}$. Hence, the results re-emphasize the importance of hedging transaction exposure, especially during volatile currency fluctuations.

The examination on whether currency forwards are more effective than options in currency hedging produces mixed results. This is clearly evident in table 2 and figure 4 . Figure 4 shows the time-series of the differences between forwards and options synthetic forwards for all the hedging horizons (i.e. $H E_{H K L}$ of forwards minus $H E_{H K L}$ of options synthetic forwards). The interpretation of figure 4 is straightforward. If the line graph is above 0 , it indicates that currency forwards are more effective than options synthetic forwards and vice-versa. If it is 0 , then currency forwards are as effective as options synthetic forwards. Table 2 (row named "percentage" and "mean differences") also tabulates the results for the same issue, but from different perspectives. We also test whether there are statistical significant differences between $H E_{H K L}$ of forwards and $H E_{H K L}$ of options synthetic forwards for the whole sample and sub-sample periods. The results are shown in table 2 (row named "significant differences"). The equation is expressed as follows:

i.e

$$
Y_{t}=\beta_{1} X_{t}+\epsilon_{t}
$$

$$
Z_{t}=\beta_{2} X_{t}+\epsilon_{t}
$$

where $T$ is the number of observations, $y_{t}$ is $b_{H K L}^{*}$ and the disturbance term $\mu_{t}$ is such that $E \mu_{t}$ $=0$, but there is no requirement that the $\mu_{t}$ is serially correlated or homogeneous. Since the calculation of $b_{H K L}^{*}$ depends on overlapping sample data, the errors terms are inevitably serially correlated and thus the Philip-Perron's test is more suitable than the conventional $\mathrm{ADF}$ test for the purpose of this research. 


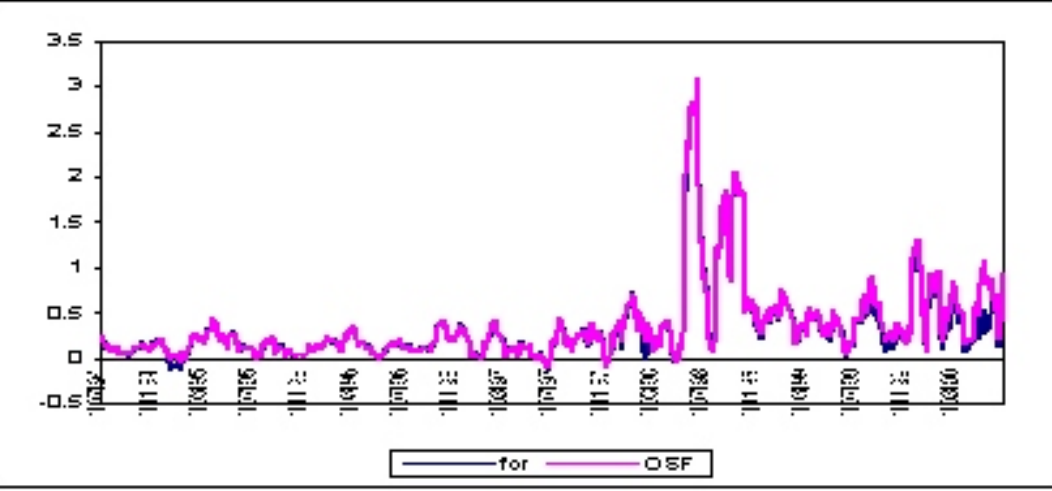

FIGURE 3a. $-H E_{H K L}$ or forwards and options synthetic forwards for 1month hedging horizon.

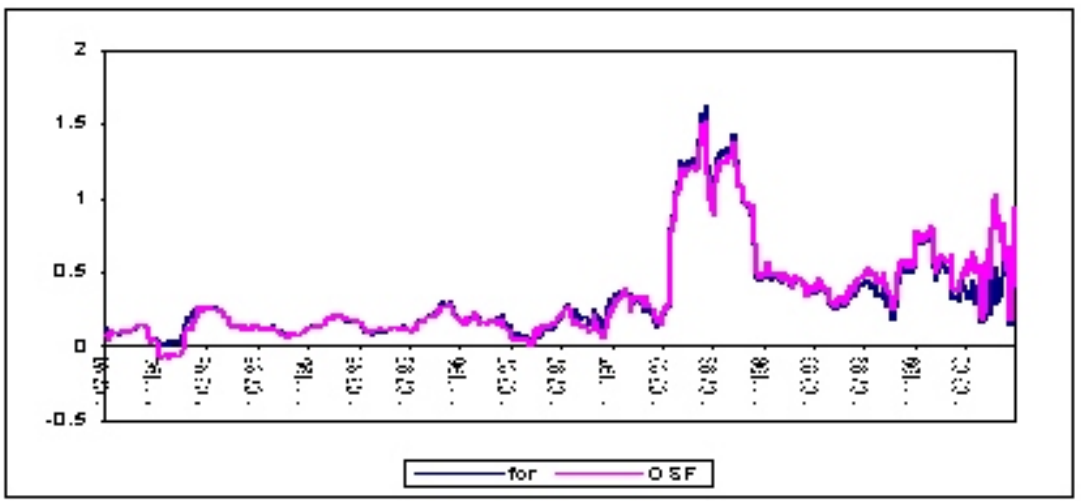

FIGURE 3b.- $H E_{H K L}$ or forwards and options synthetic forwards for 3month hedging horizon.

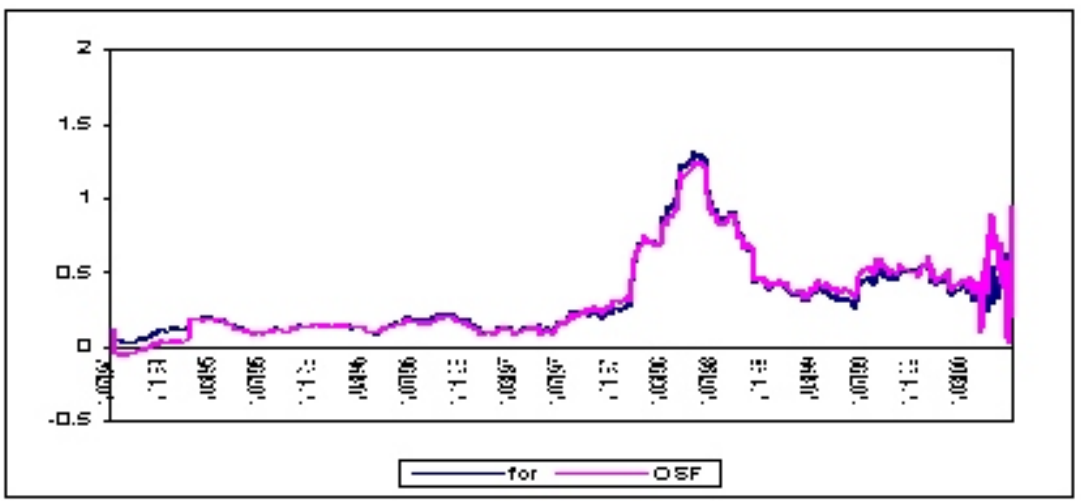

FIGURE 3c. $-H E_{H K L}$ or forwards and options synthetic forwards for 6month hedging horizon. 


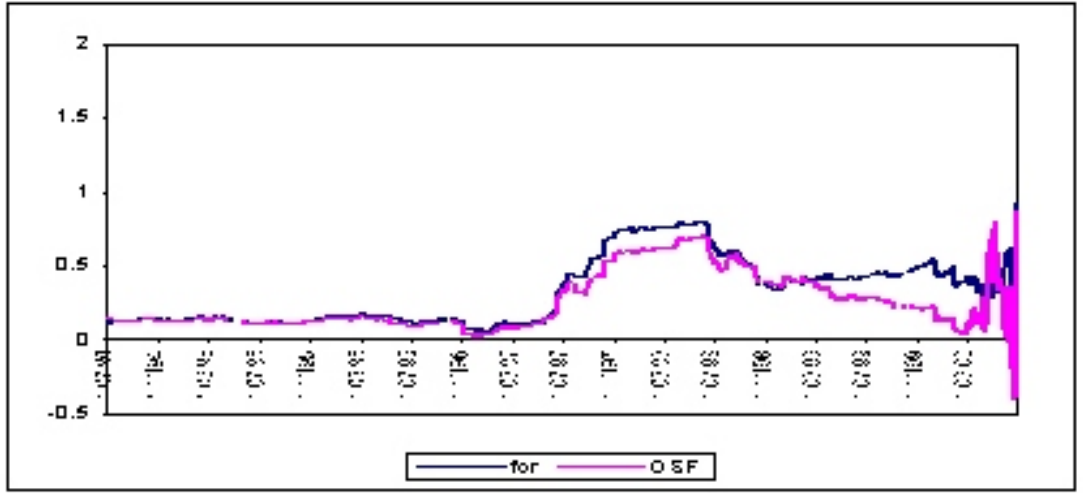

FIGURE 3d.- $H E_{H K L}$ or forwards and options synthetic forwards for 12month hedging horizon.

where $Y_{t}$ and $X_{t}$ is the respective $H E_{H K L}$ of forwards and $H E_{H K L}$ of options synthetic forwards:

$$
Z_{t}=Y_{t}-X_{t}
$$

$\beta_{2}=\beta_{1}-1$ with the null is $\beta_{1}=1$ or alternatively $\beta_{2}=0$.

Since this research adopts the moving-window procedure in calculating the daily $H E_{H K L}$, the disturbance error term $\epsilon_{t}$ are serially correlated. Thus, this research regresses equation 15 using NeweyWest's (1987) consistent estimation procedure. ${ }^{15}$

Table 2 and figure 4 show that on average, for the whole sample period of $1 / 7 / 1994$ to $30 / 6 / 2000$, forwards are superior to options synthetic forwards for $38.43 \%, 46.74 \%, 58.70 \%$ and $86.62 \%$ of the time for the respective hedging horizons of 1, 3, 6 and 12-month. During the pre-Asian Crisis, forwards are marginally superior to options synthetic forwards for $53.00 \%, 62.71 \%, 82.38 \%$ and $90.42 \%$ of the time for the respective hedging horizons of 1, 3, 6 and 12-month; while during the post- Asian Crisis, forwards are superior to options synthetic forwards

15. The Newey-West estimator of $\operatorname{VaR}(\hat{B})$ is given by:

$$
\operatorname{VaR}(\hat{B})_{\text {जम }}=\left(X^{\prime} X\right)^{-1} ?\left(X^{\prime} X\right)^{-1},
$$

where ? is generally of unknown form and adjust for both heteroscedasticity and autocorrelation. The standard errors computed according to this method are thus heteroscedasticity and autocorrelation consistent. 


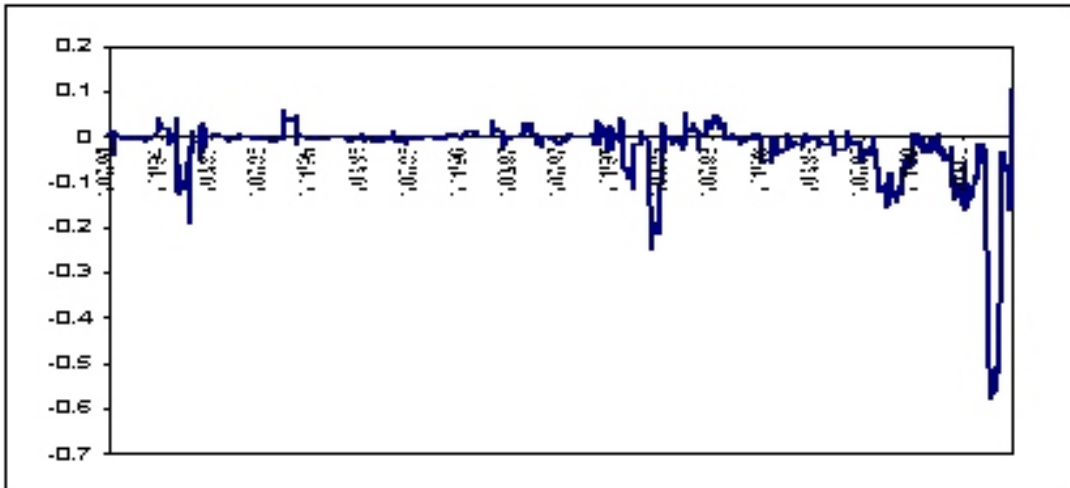

FIGURE 4a.-Differences of the $H E_{H K L}$ between forwards and options synthetic forwards for 1-month hedging horizon.

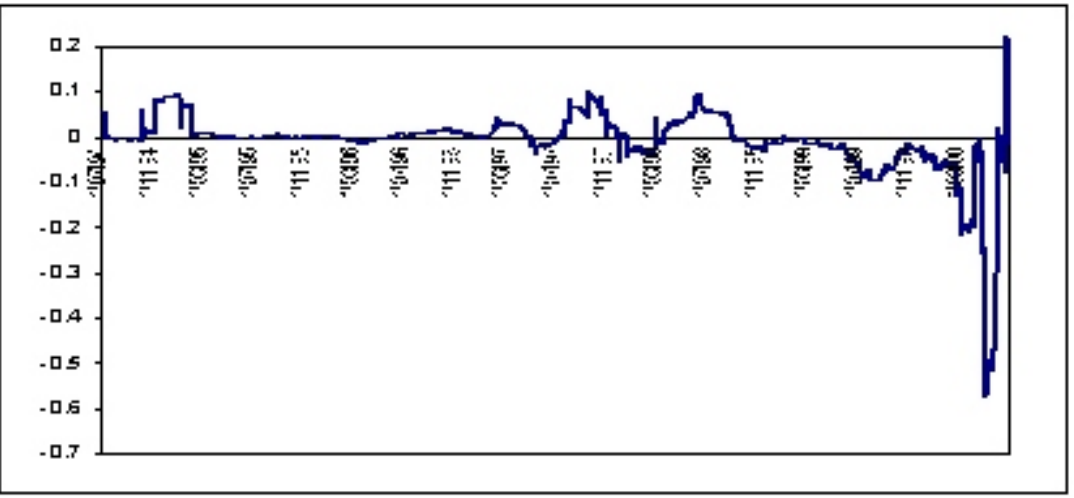

FIGURE 4b.-Differences of the $H E_{H K L}$ between forwards and options synthetic forwards for 3-month hedging horizon.

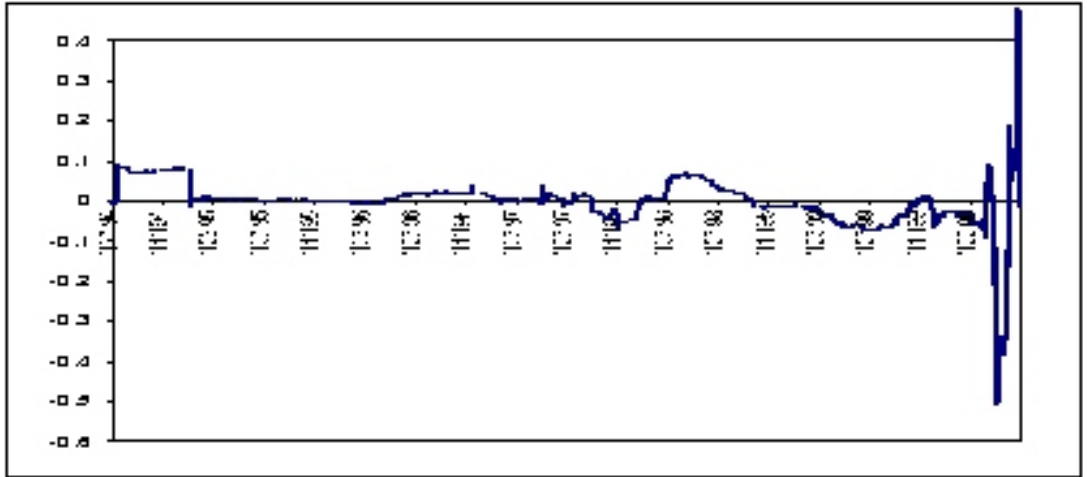

FIGURE 4c.-Differences of the $H E_{H K L}$ between forwards and options synthetic forwards for 6-month hedging horizon. 


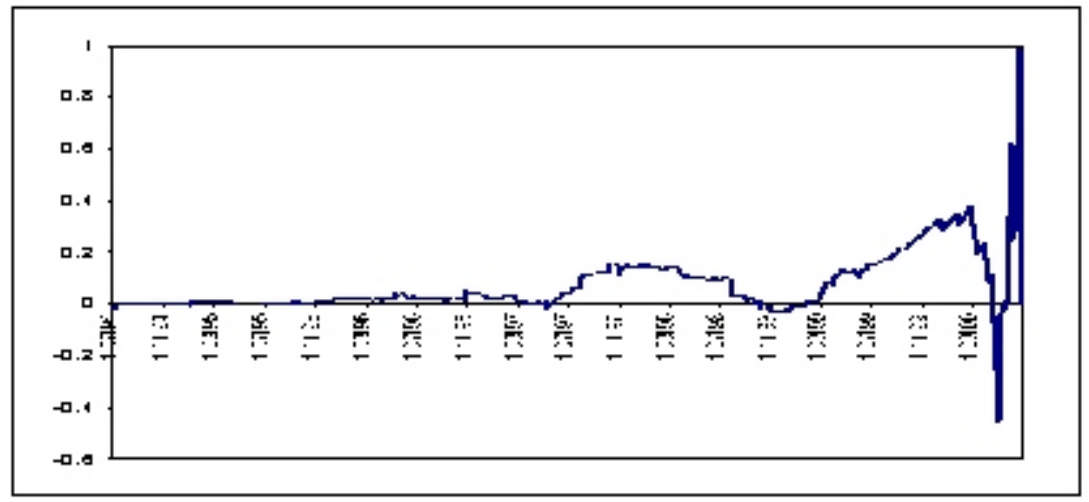

FIGURE 4d.-Differences of the $H E_{H K L}$ between forwards and options synthetic forwards for 12-month hedging horizon.

for $23.82 \%, 30.28 \%, 34.96 \%$ and $86.81 \%$ of the time for the respective hedging horizons of 1, 3, 6 and 12-month. In addition, equation 15 shows that except for the 6-month hedging horizon in the whole sample and post-Asian Crisis periods, the $H E_{H K L}$ of forwards are statistically significant different from that of options synthetic forwards at $5 \%$ level.

Overall, when the currency market is in stable state, forwards are marginally more effective than options synthetic forwards in hedging NZD/USD transaction exposure for all the hedging horizons. However, in volatile exchange rate environment, the 1,3 and 6-month options synthetic forwards are more effective. In other words, short-term NZD/USD options may replace forwards in hedging currency transaction exposure in more volatile exchange rate movements. The research findings are inconsistent with previous works by Chang and Shanker (1986), Hsin Kuo and Lee (1994) and DeMaskey (1995) who demonstrate that currency futures consistently outperform currency options in hedging currency risks. Since this research (which uses currency forwards) generates inconsistent results compared to those previous findings that mainly concentrate on currency futures, the comparison between currency forwards and currency futures and the argument put forth by Lien (1997) and Kwok (1987) should therefore be interpreted with caution. In addition, for longer transaction exposure of 1 year and when the currency market is volatile, the forwards are more effective than options synthetic forwards. This is quite surprising as we would expect the results to be opposite of what we actually observe due to the flexibility and nature of the options in hedging long term transaction exposure in volatile exchange markets compared to that 
of the forwards. We caution that this could be because we use the GARCH $(1,1)$ approach to model the volatility term of the options. Hence, the in-sample estimation period used in forecasting the volatility term could be "outdated" and "irrelevant" when the NZD/USD regime switches from non-volatile to more volatile condition. However, the forwards rates may be better in capturing the future prices of the exchange rate. In other words, the market is "efficient" where market participants "correctly" forecast the volatile exchange rate and interpolate it into the forward prices. ${ }^{16}$ This may explain why the forwards are more effective than the options synthetic forwards in hedging long term transaction exposures in a volatile exchange market. Further research on this issue is warranted.

In order to test whether the results are robust to the $\Theta$ parameter, this research re-runs the test with $\Theta=0.5$ and $\Theta=6 .{ }^{17}$ The former represents a less risk-averse exporter, while the latter represents a more risk-averse exporter. Because more risk-averse exporters allows a larger marginal rate of substitution of risk reduction for returns, their choice of optimal hedge ratios are expected to reduce more proportional risk and hence produce a higher hedging effectiveness. Indeed, the resulting $H E_{H K L}$ values for an exporter with $\Theta=6$ are larger than those of an exporter with $\Theta=2$ and followed by $\Theta=0.5$. For instance, for a 1 and 12-month hedge using forwards, the $H E_{H K L}$ of an exporter with $\Theta=6$ is 1.037 and 1.022 respectively for the whole sample period considered, but the values reduced to only 0.070 and 0.062 for an exporter with $\Theta=0.5$. In addition, the analyses of the comparisons between the forwards and the options are parallel to the earlier results which use $\Theta=2$. Currency forwards provide marginally higher hedging effectiveness than options synthetic forwards in stable market, but in the event of more volatile market, options synthetic forwards is more effective to hedge short term transaction exposure of 1,3 and 6-month. For 12-month hedging horizon, forwards are still the better derivatives in terms of hedging effectiveness.

16. Indeed, the use of implied volatility for the option prices could potentially yield different results. In other words, it could be the case that options are superior to forwards in hedging 1 year transaction exposure had the implied volatility parameters been used in deriving options synthetic forwards instead of GARCH (this, of course, depends on the assumption that the options players correctly forecast the sudden volatile exchange rate and interpolate it in pricing the options prices). Unfortunately, as this research have noted earlier, the NZD/USD currency options data are unobservable in the primary or secondary markets and hence warrants the unavailability of the implied volatility parameter.

17. The complete sets of results and figures are not presented due to space constraint. They are available from the authors upon request. 


\section{Conclusion}

This research compares the ex-ante hedging effectiveness provided by currency forwards and options markets for a New Zealand exporter in hedging NZD/USD transaction exposure. The hedging effectiveness measure is based on the rule of expected utility maximization while the optimal hedge ratios are determined by maximizing the exporter's negative utility function. The analysis demonstrates that for an ordinary risk-averse exporter hedging prior to the 1997 Asian Crisis, the 1-, 3- or 6-month forwards markets are marginally more effective than options synthetic forwards in hedging the NZD/USD transaction exposures. However, during and after the Asian Crisis, options synthetic forwards are more effective than forwards contracts. For longer hedging horizon of 12-month, forwards consistently outperform options synthetic forwards. Robustness tests provide evidence that the results on the choice of optimal derivatives instrument are insensitive to a more riskaverse exporter.

These research findings suggest that an exporter who is facing shortterm, NZD/USD transaction exposure and a less volatile exchange rate environment should choose the forwards markets. In the event of an impulsive exchange rate fluctuation, the exporter should opt for the options contracts. This situation also implies that the options markets may replace the role played by the conventional currency forwards markets in hedging transaction exposure when the exchange rate changes exhibit volatile oscillations. Meanwhile, if the exporter's transaction exposures are of a long-term nature, she should always use the forwards markets. Furthermore, regardless of which derivative is chosen, the typically risk averse exporter should always hedge her transaction exposures as the utility derived from a hedged position is higher than that derived from an unhedged position.

\section{References}

Anderson, R. W., and Danthine, J.-P. 1980. Hedging and joint production: Theory and illustration. Journal of Finance 35: 487-498.

Anderson, R. W., and Danthine, J.-P. 1981. Cross hedging. Journal of Political Economy 89: 1182-1196.

Baillie, R.T., and Bollerslev, T. 1989. Common stochastic trends in a system of exchange rates. Journal of Finance 44: 167-181.

Berkman, H.; Bradbury, M.E.; and Magan, S. 1997. An international 
comparison of derivatives use. Financial Management 26: 69-73.

Biger, N., and Hull, J. 1983. The valuation of currency options. Financial Management 12: 24-28.

Bollerslev, T. 1986. Generalized autore gressive cond itional heteroscedasticity. Journal of Econometrics 31: 307-334.

Boothe, P., and Glassman, D. 1987. The statistical distribution of exchange rates. Journal of International Economics 22: 297-319.

Chang, S.K., and Shanker, J. 1986. Hedging effectiveness of currency options and currency futures. The Journal of Futures Markets 6: 289-306.

Chang, S.K., and Shanker, J. 1987. A risk return measure of hedging effectiveness: A comment. Journal of Financial and Quantitative Analysis 22: $373-376$.

Cox, J.C., and Rubenstein, M. 1985. Options Markets. New Jersey: Prentice Hall, Inc.

Daigler, R.T. 1994. Financial Futures and Options Markets: Concepts and Strategies. New York: Harper Collins College Publishers.

Das, S. 1997. Estimating volatility. In Das, S. (eds). Risk Management and Financial Derivatives: A Guide to the Mathematics. New York: McGrawHill.

De Jong, A.; De Roon,R.; and Veld, C. 1997. Out-of-sample hedging effectiveness of currency futures for alternative models and hedging strategies. The Journal of Futures Markets 17: 817-837.

DeMaskey, A. L. 1995. A comparison of the effectiveness of currency futures and currency options in the context of foreign exchange risk management. Managerial Finance 2: 40-51.

Dickey, D.A., and Fuller, W. A. 1979. Distribution of the estimators for autoregressive time series with a unit root. Journal of the American Statistical Association 74: 427-431.

Diebold, F.X.; Hickman, A.; Inoue, A.; and Schuermann, T. 1997. Converting 1-day volatility to h-day volatility: Scaling by $\sqrt{h}$ is worse than you think. Downloadable at http:www.ssc.upenn.edu/ diebold/

Duan, J.-C. 1995. The GARCH option pricing model. Mathematical Finance 5: $13-32$.

Eaker, M. R.; Fabozzi, F. J.; and Grant, D. 1996. International Corporate Finance. Florida: The Dryden Press.

Ederington, L. 1979. The hedging performance of the new futures markets. Journal of Finance 34: 157-170.

Engle, R. 1982. Autoregressive conditional heteroscedasticity with estimates of the variance of U.K. inflation. Econometrica 50: 987-1008.

Engle, R. F.; Hong, T.; Kane, A.; and Noh, J. 1993. Arbitrage valuation of variance forecasts. Advanced Futures and Options Research 6: $393-415$.

Engle, R.; Kane, A.; and Noh, J. 1993a. A test of the efficiency for the S\&P 500 index option market using variance forecast. NBER W orking Paper No 4520 and UCSD Discussion Paper No. 93-32. 
Engle, R.; Kane, A.; and Noh, J. 1993b. Index option price with stochastic volatility and the value of accurate variance forecasts. NBER W orking Paper No 4519 and UCSD Discussion Paper No. 93-43.

Engle, R.; Kane, A.; and Noh, J. 1994. Forecasting volatility and option prices of the S\&P Index. Journal of Derivatives 2: 17-30.

Figlewski, S. 1999. Lecture Note Class 27: Value at risk, derivatives risks and model risk. Downloadable at www.stern.nyu.edu/ sfiglews/ HomeCourses.html.

Garman, M.B., and Kohlhagen, S.W. 1983. Foreign currency option values. Journal of International Money and Finance 2: 231-237.

Gjerde, O. 1987. Measuring hedging effectiveness in a traditional one-periodic portfolio framework. Journal of Futures Market 7: 663-674.

Grabbe, J. O. 1983. The pricing of call and put options on foreign exchange. Journal of International Money and Finance 2: 239-253.

Grossman, S.J., and Shiller, R.J. 1981. The determinants of the variability of stock market prices. American Economic Review 71: 222-227.

Hammer, J.A. 1988. Hed ging and risk aversion in the foreign currency market. The Journal of Futures Markets 8: 657-686.

Heston, S.L. 1993. A closed form solution for options with stochastic volatility with application to bond and currency options. The Review of Financial Studies 6: 327-343.

Hill, J., and Schneeweis, T. 1982. Forecasting and the hed ging effectiveness of pound and mark forw ard and futures markets. Management International Review 22: 43-52.

Howard, C.T., and D'Antonio, J.D. 1984. A risk-return measure of hedging effectiveness. Journal of Financial and Quantitative Analysis 19: 101112.

Howard, C.T., and D'Antonio, J.D. 1987. A risk-return measure of hedging effectiveness: A reply. Journal of Financial and Quantitative Analysis 22: 376-381.

Hsieh, D.A. 1988. The statistical properties of daily foreign exchange rates: 1974 - 1983. Journal of International Economics 24: 129-145.

Hsieh, D.A. 1989. Modeling heteroscedasticity in daily foreign exchange rates. Journal of Business and Economics Statistics 7: 307-317.

Hsin, C.-W.; Kuo, J.; and Lee, C.-F. 1994. A new measure to compare the hedging effectiveness of foreign currency futures versus options. The Journal of Futures Markets 14: 685-707.

Jacque, C.M., and Bera, A.K. 1987. A test of normality of observation and regression residuals. International Statistical Review 55: 163-172.

Johnson, L.L. 1960, The theory of hedging and speculation in commodity futures. Review of Economic Studies 27: 139-151.

Junkus, J.C., and Lee, C.F. 1985. Use of three stock index futures in hedging decisions. Journal of Futures Markets 5: 201-222.

Kallberg, J.G., and Ziemba, W.T. 1983. Comparison of alternative utility functions in portfolio selection problems. Management Science 29: 1257 
-1276 .

Kwok, C.Y. 1987. Hedging foreign exchange exposures: Independent vs. integrative approaches. Journal of International Business Studies 18: 3351.

Lien, D.D.-H. 1997. Forwards or options: A comparison. The Journal of Futures Markets 17: 975-978.

Naidu, G. N., and Shin, T. S. 1981. Effectiveness of currency futures market in hedging foreign exchange risk. Management International Review 21: 5 -16 .

Newey, W., and West, K. 1987. A simple positive semi-definite heteroscedasticity and autocorrelation consistent covariance matrix. Econometrica 55: 703-708.

Phillips, P., and Perron, P. 1988. Testing for a unit-root in time series regression. Biometrika 75: 335-346.

Pratt, J. W. 1964. Risk aversion in the small and in the large. Econometrica 32: $122-136$.

Prevost, A.; Rose, L.; and Miller, G. 2000. Derivatives usage and financial risk management in large and small economics: A comparative analysis. Journal of Business, Finance and Accounting 27: 733-759.

Sarwar, G., and Krehbiel, T. 2000. Empirical performance of alternative pricing models of currency options. The Journal of Futures Markets 20: 265-291.

Shastri, K., and Tandon, K. 1986. Valuation of foreign currency options: Some empirical tests. Journal of Financial and Quantitative Analysis 21:145160.

Stein, J. 1961. The simultaneous determination of spot and futures prices. American Economic Review 51: 1012-1025.

Ware, R., and Winter, R. 1988. Forward markets, currency options and the hedging of foreign exchange risk. Journal of International Economics 25: 291-302.

West, K. D.; Edison, H. J.; and Cho, D. 1993. A utility-based comparison of some models of exchange rate volatility. Journal of International Economics 35: 23-45.

Witt, H. J.; Schroeder, T.C.; and Hayenga, M.L. 1987. Comparison of analytical approaches for estimating hedge ratios for agricultural commodities. The Journal of Futures Markets 7: 135-146.

Working, H. 1953a. Futures trading and hedging. American Economic Review 43: 314-343.

Working, H. 1953b. Hedging reconsidered. Journal of Farm Economics 35: 547-549.

Working, H. 1962. New concepts concerning futures markets and prices. American Economic Review 52: 431-459. 